\begin{tabular}{ccc}
\hline & International Journal of Engineering \&Technology, $7(3.12)(2018) 198-200$ \\
SPC & Website www.sciencepubco.com/index.php/IJET \\
Research paper & Technology \\
\hline
\end{tabular}

\title{
Cost Effective Construction for Low Income Earners with MRTB and MFS
}

\author{
S.S.R.Swathi ${ }^{1}$, G.Varuna Lakshmi ${ }^{2}$, D.Muthu ${ }^{3}$, C.Venkatasubramanian ${ }^{4}$, M.Nagavalli $^{5}$ \\ ${ }^{1,2}$ Student-M.Tech in Construction Engineering and Management (Integrated), SASTRA Deemed-tobe-University, Thanjavur(Dt) \\ ${ }^{3,4}$ Assistant Professor, School of Civil Engineering, SASTRA Deemed-tobe-University, Thanjavur(Dt) \\ ${ }^{5}$ Student-B.Tech in Civil Engineering, SASTRA Deemed-tobe-University, Thanjavur(Dt) \\ *Corresponding Author Email: ${ }^{1}$ srswathirohita74@gmail.com
}

\begin{abstract}
India is a developing country having 14\% (Pew Research Centre) population of low income group. The desire to own a house especially for low income and middle class families has become a virtual reality. Hence it is required to go in for an innovative, eco-friendly and cost efficient technology for raising of houses enabling the ordinary persons to build houses at owing to their financial status. The materials and techniques which are adopted have to be durable, economical and accepted by users. This study of low cost housing focuses mostly on personal satisfaction levels and the need of quality, particularly with regard to the place of abode. Hence, to provide the basic needs to the low income earners, this economical housing concept with minimum financial statement/investment has been suggested. The reduced construction cost through suitable management plans is obtained by appropriate use of locally available materials, labour and technology without compromising on the strength and life of the structure. In this study, it has been found that about $12 \%$ of total bricks and $22 \%$ of materials can be saved by using Modified Rat Trap Bond for walls and Modified Filler Slab for roofs respectively, which may be applied practically for government low cost dwellings.
\end{abstract}

Keywords: Cost effective, Low income earners, Modified Rat Trap Bond, Modified Filler Slab.

\section{Introduction}

Owning a house has always been a dream for all groups of people. But this is not met among low income group people. "Necessity is the mother of invention" and hence cost effective construction technology is essential. Due to hike in the basic cost of building materials and labour in the past 20 years, over $50 \%$ inflation has taken place in the project cost. To optimise the project cost, various cost control techniques are being introduced nowadays. This brings in the necessity to scrutinize these techniques and construction materials periodically that ensures innovative and effective techniques.

\section{Literature Review}

Vivian W. Y. Tam(2011) comparing the low cost technologies and traditional construction cost for durability and strength of the structure. Methods for lintel, foundation, roofing and walling are collated. Priority for the decrease in construction cost is scrutinized. Thereby reducing the cost of construction for effective approach to the industry..

BredenoordJ(2016) the imperishable goals for minimization of the construction cost is achieved. The measures for physical evolvement of the neighbourhoodare vital, similar to the improvement of the community. it also includes support for the last incorporate help for group based associations, little lodging cooperatives (or comparable types of collaboration) and individual families - or little gatherings - that manufacture and enhance their homes incrementally.Sufficient arranging, social association and collaboration are preconditions for accomplishing maintainability in incremental lodging.

Ashish S. Yeolekar (2017) states with that the rapid growth of population arises a major crisis of land deficiency in urban sector. Lack of basic amenities, housing loans, raw materials etc. are mentioned as other shortcomings in the paper. Urbanization has brought about individuals more and more living in ghettos and homesteader settlements and has crumbled the lodging states of the monetarily weaker segment of society, which is fundamentally because of elevated costs of land in urban sectors that have constrained financially backward segment of the general public to possess the minimal assets. Thinking about these components, there, at present, exists a wide gap between the request and supply of lodging in urban territories. Consequently, it has turned into a need for creating nation like India to embrace savvy, inventive lodging for the development of houses for empowering the general population to build houses at reasonable cost. Our project expects to diminish the cost of working by supplanting standard material with most recent one and propose new philosophy which will lessen cost and also don't influence the quality of the structure.

RINKU TAUR(2009) This paper plans to bring up the different parts of pre-assembled fabricating procedures for ease lodging by featuring the distinctive construction strategies, and the conservative favourable circumstances accomplished by its appropriation. In a building, the establishment, dividers, entryways and ventilators, floors and rooftops are the most critical segments, which can be broken down independently in light of the necessities thus, enhancing the speed of development and decreasing the development cost. The real current techniques for development frameworks considered here are in particular, basic piece dividers, mortar less square dividers, pre-assembled material 
segments like precast RC boards, precast empty solid boards, precast cement/Ferro bond boards are considered.

\section{Materials and Technology}

\section{A) Materials}

- Cement - OPC, Specific Gravity 3.15

- Fine Aggregate - River Sand, Specific Gravity 2.4

- Coarse Aggregate- Crushed granite chips, Specific Gravity 2.46

- Straw cement cake- mixture of raw straw and cement poured in the mould (for 48 hours )of $10 \times 10 \mathrm{~mm}$.

- Brick- $22 \mathrm{~mm} \times 110 \mathrm{~mm} \times 75 \mathrm{~mm}$

- Reinforcement bars- 6mm diameter Mild Steel

- Required amount of water is used in mixing.

\section{B) Technology}

\section{I) Modified Rat Trap Bond}

Rat trap bond is a sort of brick wall masonry where the bricks are placed on their edges such that the shiner and rowlock are evident on the face of masonry. This creates an internal cavity intercepted by the rowlock. So this reduces the quantity of mortar and bricks reasonably. The cavity present provides insulation, in turn providing a lower temperature inside. Thus these features pertain to the Green Building aspects. Rat Trap Bond is categorisedunder modular type masonry. This enables the dimensions of walls and openings in them to be in multiples of modules. Alignment differs Rat Trap Bond from Modified Rat Trap Bond. In a normal Rat Trap Bond, the coarse contains one header followed by a stretcher and so on. But in case of MRTB, a stretcher is followed by two headers and this increases the stability of the coarse. Two trials were conducted of which the first trial has a discrepancy of improper vertical alignment. Second trial was experimented placing a 3/4th brick at the beginning and hence the alignment was rectified. Normal English bond wall was also constructed for the sake of comparison of the compressive strength.

\section{II) Modified Filler Slab}

The concept of filler slab came into play due to the limitations like heavy self weight which increases the cost of construction of the foundation beneath.MFS is provided with internal cavities, which improves thermal ease in addition to the above disadvantage. The filler materials are such that they relatively maintain the structural durability, strength and stability. The water absorption percentage should be verified to prevent suction of water from concrete which may affect the strength.

The materials so chosen are light weight, non reactive and easy on the pocket like low grade Mangalore tiles, hollow concrete blocks, shells of coconut, pots from clay etc. National Building Code 2005 approves the relevant material, construction, design and the anticipated method.

\section{Experimental Analysis}

\section{Compressive Strength}

According to IS:13311 part $2-1992$, the popularly used compressive strength is the rebound hammer test. When the rebound hammer is struck against a solid mass, the elastic mass in it gets rebounded. This value in the anvil furnishes us with the hardness of the material tested. The body of the hammer affords the index of rebound and a graph which indicates the compressive strength.

\section{Results and Discussion}

\section{MFS}

The rebound hammer test was used to test the Modified Filler Slab against the compressive strength. it was conducted on the 14th and the 28th day on both MFS and Normal slab for comparison purpose.

On 14th day MFS showed considerable variation at different points while conventional slab displayed less deviation. The maximum compressive strength noted was $20 \mathrm{MPa}$ ad that of normal slab was $23 \mathrm{MPa}$.On the other hand, the strength turned out to be $23 \mathrm{MPa}$ and $28 \mathrm{MPa}$ respectively on 28 th day. Thus MFS technique can be adopted for structures less than or equal to two storey residential building only.

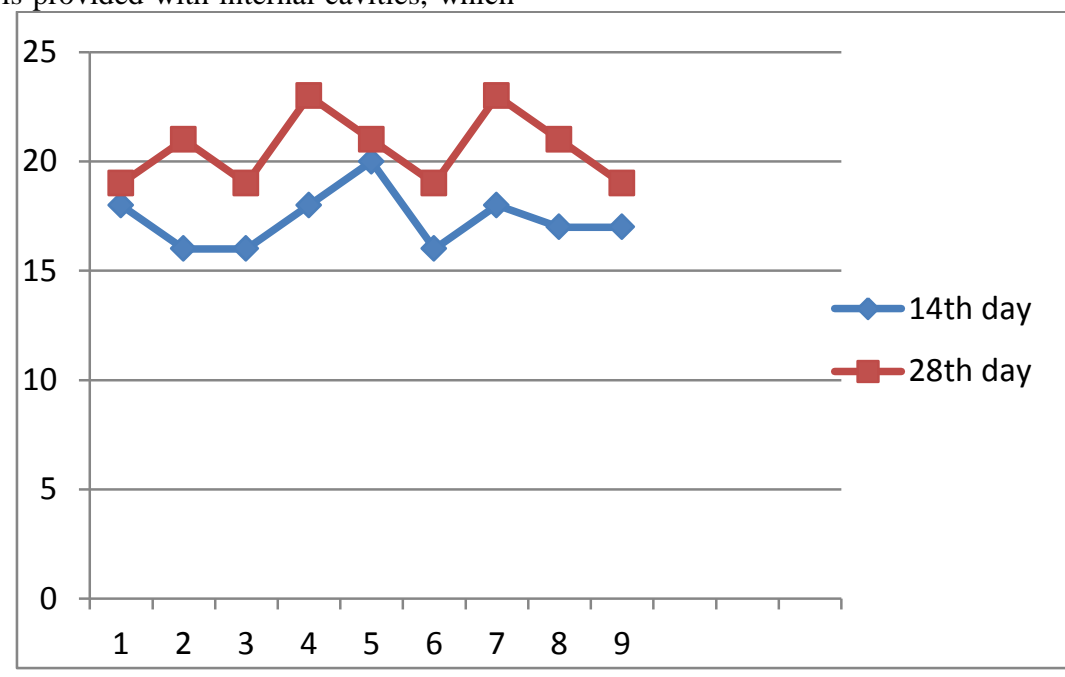

Fig. 1: Comparison of strength in different points of MFS 


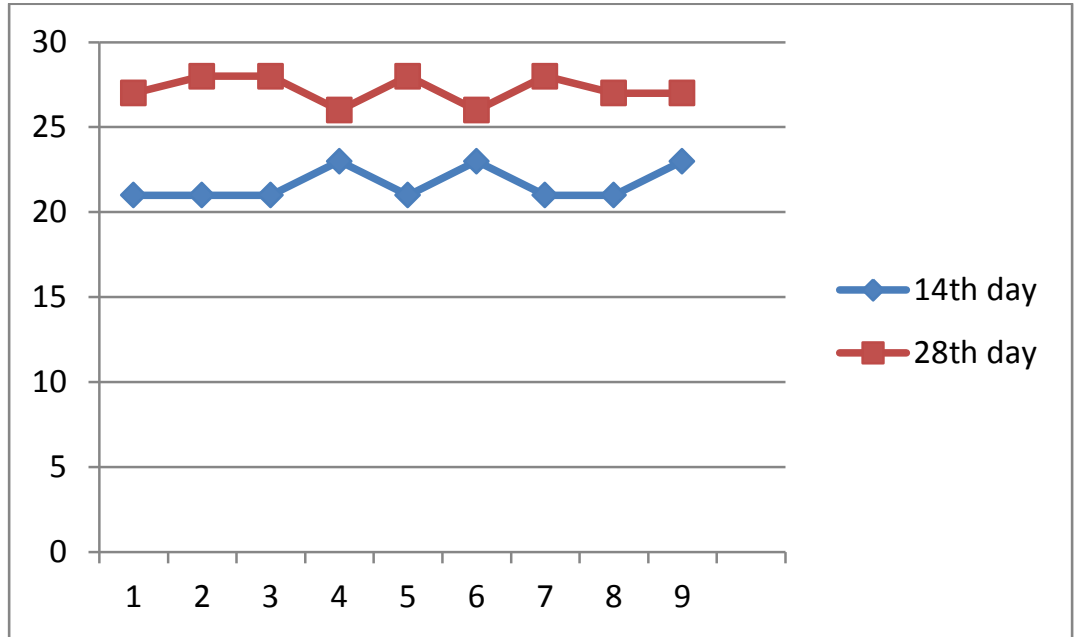

Fig. 2: Comparison of strength in different points of NORMAL SLAB

\section{MRTB}

In case of masonry wall the rebound hammer test gave the approximate compressive strength of MRTB and conventional masonry. The test was carried out at the vertical top, horizontal right, horizontal left of the masonries. The second trail of MRTB showed $18 \mathrm{MPa}, 22 \mathrm{MPa}, 26 \mathrm{MPa}$ at the respective points on 20 th day similar to that of conventional masonry. On the 30th day, MRTB attained a maximum of $22 \mathrm{MPa}, 26 \mathrm{MPa}, 26 \mathrm{MPa}$ at their respective spots. Whereas the masonry proved $20 \mathrm{MPa}, 27 \mathrm{MPa}$, $27 \mathrm{MPa}$. These values conclude that MRTB can be used only upto two storey as a load bearing wall.

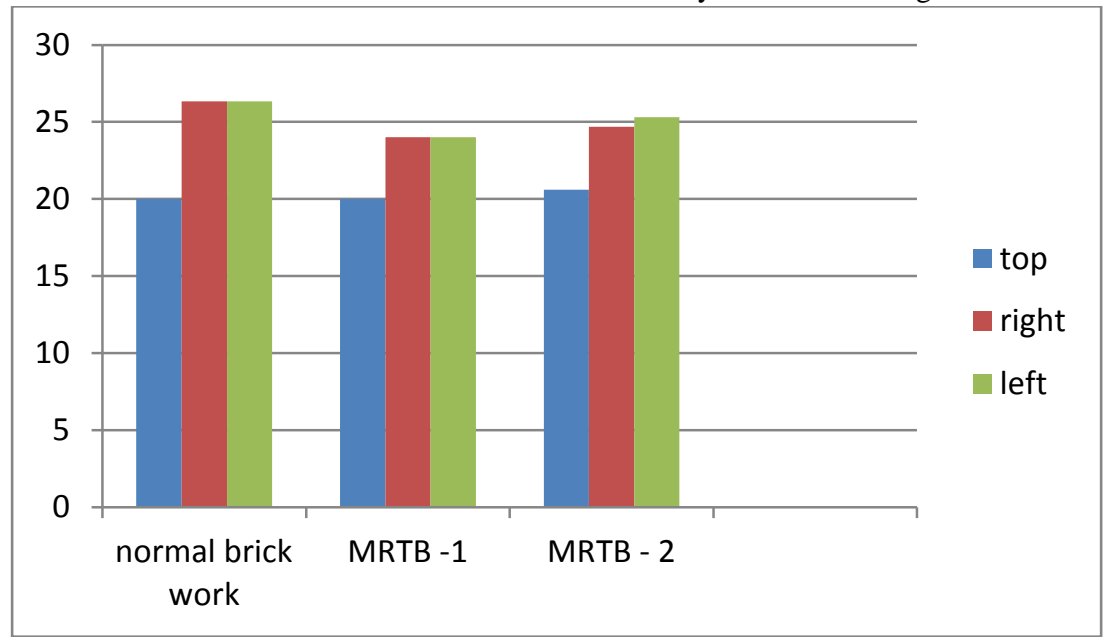

Fig. 3: Comparison strength results on $30^{\text {th }}$ day

\section{Inferences}

\section{a) Modified Rat Trap Bond}

The quantity of cement mortar consumed went down considerably due to the reduction in number of bricks. The stability parameter remains unaffected. The cavities present does not conduct much heat from outside in. Three fourth of a brick is added to every bond where the nailing points are likely to occur. All these contributed to approximately $12 \%$ drop of quantity of brick conventionally used.

\section{b) Modified Filler Slab}

The interiors of the house are relatively cooler throughout the year due to the presence of cavity between the filler materials and/or in itself. Around 25\% of concrete is less used owing to $30 \%$ lesser carbon emission thus going green. The texture of the material so chosen goes well with the ceiling pattern enhancing the interior.

\section{References}

[1] Garg R.K., Garg N. K. \&Batra Y. K.(2004), "Sanitation and Waste Water Disposal Systems in Rural Areas", Journal of Indian Building Congress, Vol. 11, No. 2, 2004; Seminar on "Up gradation of Housing \& Amenities in Rural Areas", Bhubaneswar, December, 22nd-23rd2004. BMTPC. ACSGE-2009, Oct 25-27, BITS Pilani, India

[2] Bredenoord, J, "Sustainable Housing and Building Materials for Low-income Households", J ArchitEng Tech, 2016 ,5(158), 2.

[3] IS: 456 (2000). Indian Standard Plain and Reinforced Concrete Code of Practice. Bureau of Indian Standards, New Delhi

[4] IS: 383 (1970). Indian Standard Specification for Coarse and Fine aggregates from Natural Sources for Concrete (Second Revision). Bureau of Indian Standards, New Delhi.

[5] IS: 10262 (1982). Recommended Guidelines for Concrete Mix Design. Bureau of Indian standards, New Delhi.

[6] IS: 516 (1959). Indian Standard Method of Tests for Strength of Concrete. Bureau of Indian Standards, New Delhi

[7] Tam, V. W. (2011). Cost effectiveness of using low cost housing technologies in construction. Procedia Engineering, 14, 156-160. 